RUTH AYLETT

\title{
AND THEY BOTH LIVED HAPPILY EVER AFTER?
}

\author{
Digital stories and learning
}

\section{INTRODUCTION}

In this paper we consider the role of story in digital technology enhanced learning and the issues involved in constructing digital narrative learning environments. We will see that story has played an important role in education for a very long time, well pre-dating the use of digital technologies, and can be closely related to a number of theoretical approaches to learning. However story has recently become a much more significant topic for research, not only in education and digital technology, but also in other fields, such as knowledge management, and we examine why it has become such a central concern.

The paper then looks at the existing use of story in fielded educational applications, and questions how far it has actually been used as an essential mechanism - producing a narrative learning environment - rather than merely as motivational support. The relationship between story and computer games is an important issue here. We argue that the interactivity of digital media raises fundamental problems for the use of story that are still challenging researchers, and look at the various approaches to dealing with these problems, citing a number of example systems.

Finally, we discuss the direction in which the technology is moving - what it offers now and what it may offer in the near future, and what technology support is currently available for creating digital narrative learning environments.

\section{THE IMPORTANCE OF STORY}

The interest in narrative learning environments represents a recognition that learning is not just about knowledge, but also about motivation, engagement and social interaction, all areas in which story can play a central role. Indeed it is argued (Young, 2001) that story represents a fundamental structuring of human experience, both individual and collective. Autobiographical memory (Bruner, 1987) - the internalisation of our own past experience - can be partly thought of as stories about the self, while myth and legend - both story-forms - predated science and history as explanations for the state of the natural world.

It is nevertheless very difficult to produce an unambiguous and generally accepted definition of story. Here we reference that of Sarbin: 


\section{RUTH AYLETT}

A story is a symbolised account of actions of human beings that has a temporal dimension. The story has a beginning, middle, and an ending...The story is held together by recognisable patterns of events called plots. Central to the plot structure are human predicaments and attempted resolutions. (Sarbin, 1986: 3)

Alternatively we may see story as the interplay between the two poles of character and causation. From characters come the aspects of personality, emotional state and social standing, linked to causation via motives, intentions, plans and actions. From causation come the aspects of temporality and sequence, linked to characters by events and their outcomes. These twin preoccupations with character and causation are the everyday currency of human engagement with the world as the prevalence of anthropomorphism and the widespread imputation of intentional agency to the natural world demonstrate. However, in story the emphasis on one or other pole varies according to period and genre: for example Greek tragedy, with its dominant theme of the workings of Fate was more dominated by causation than a modern soap opera in which character interaction is the source of the majority of causation.

The extent of this interplay has an effect on how far the result is experienced as story at all: at one end of the spectrum, character disconnected from causation is experienced more as a cocktail party than a story (as in many online chat environments) while at the other, causation disconnected from character is experienced more as a game or puzzle than a story.

Note that in common with much of narrative theory until post-structuralism, the definition given by Sarbin appears to view story as an artefact: a novel, a play, a film. This is what one takes from the phrase "a symbolised account of actions". As we will see later, an artefact-based view of story becomes problematic in an interactive medium such as a digital narrative learning environment. However, from a perspective centred on learning, one can in any case take a view of story as a process of internal structuring of experience; of sense-making via narrative organisation. Here, story is not so much the novel, play or film as the internal structure that results from reading or watching: the result of what we have termed the storification process (Aylett, 2000), through which this internal narrative is constructed.

We may take this as a specific consequence of the more general constructivist argument that people are not passive recipients of their experience but active constructors of their own reality through mental activity (Piaget, 1972). It is also argued (Bednar et al, 1991) that in order for this process of active sense-making to take place and transfer outside of the classroom, learning must be situated in a rich context, reflective of the real world. Story is a specific mechanism through which the real world can be created in the imagination of learners so as to take on a virtual existence in the classroom. 
AND THEY BOTH LIVED HAPPILY EVER AFTER?

\section{Story and learning}

As we have seen, the power of story as a structuring mechanism for personal and social experience is central to constructivist theory: it can be more specifically related to the approaches of experiential learning and dynamic goal-based learning.

Experiential learning theory defines learning as "the process whereby knowledge is created through the transformation of experience. Knowledge results from the combination of grasping and transforming experience" (Kolb, 1984, p. 41). An implementational consequence is the need to create learner experiences, and while field studies, experiments and practical exercises or projects are all widely used as a result, there are many experiences one would like to give learners which are just not feasible for reasons of safety, expense, accessibility and so on. As we have just argued, story is one way of extending the range of experiences that can be offered to learners, for example through the use of role-play. Role-play is especially significant where the nature of the targeted experience depends on the dynamic decisions of participants and where social interaction, or even conflict is a central concern (for example Vincent \& Shepherd, 1998).

In educational role-play, social interaction is used as the stimulus for challenging and changing existing beliefs (Piaget, 1972) and can result in significant behavioural changes (Lewin, 1951) making it highly relevant for social and emotional learning (Davison \& Arthur, 2003; Henriksen, 2004). Thus character has at least an equal importance with causation. The basic premise of educational role-play is that it is easier to empathise with how another person might feel under certain circumstances if one has experienced something similar, even symbolically as part of a role-play (Robertson \& Oberlander, 2002). It is therefore a paradigmatic example of experiential learning but with equally strong constructivist elements. However it can also be difficult to support role-play in the classroom situation (Brookfield, 1990), so that its use has to be very carefully managed.

Dynamic goal-based learning may be defined as a learning strategy that builds on the motivation involved trying to reach a specific goal. The focus here is on causation rather than on character and works from the premise that in attempting to achieve goals in a virtual world - especially ones they have set themselves - a learner will be motivated to acquire the relevant skills and in the process the underlying knowledge and understanding. As with role-play, with which it is often allied, this is seen as especially true where the virtual world is dynamic and reflexive, that is, continually constructed by the learner's actions (Linser et al, 1999). Insofar as story supplies the motivational causal framework, it can be successfully used for this learning strategy, though games worlds are also widely used.

In educational practice, story has been widely used in subjects where temporal complexity and social interaction are significant issues. These include language development, both native and other; literature study, in which story itself may be the study topic; and history, which also has, as its name suggests, an intrinsic narrative component, especially in the evaluation of sources and the development 
of historical empathy, an explicit learning objective in the UK National Curriculum for history. Social sciences - especially politics and sociology, management science and business studies - have all used case studies and role-play extensively. Personal, social and health education, in which the pedagogical aims involve attitudes and behaviours and not just knowledge, has also applied role-play widely, as well as Theatre in Education productions. Story has even been applied in some parts of science in order to increase motivation through, for example, discovery stories, or famous scientist stories.

\section{Three uses of story}

It becomes clear from examining the various subject domains in which non-digital story is found that not all uses of story in education are identical. Here we distinguish three different approaches that might be carried over into digital application.

The first approach is that of story-telling to the learner, in two classical variants, discussed by Aristotle (330 BC). In one, a first-person narrator controls story creation, and the mode of story is essentially that of telling. The personality and expressive behaviour of the narrator form a significant part of this type of storytelling as an experience and raise issues of trust: whether we are prepared to accept the narrator's perspective; as well as affective engagement: whether the narrator is able to draw us into the world of the story.

The other classic approach is of course that of third-person showing, in which characters tell the story by enacting it. Again personality and expressive behaviour are central, but the existence of multiple characters may support a number of different story-perspectives. In both cases the existence of a teller implies the existence of a listener or spectator who does not themselves have any control over the unfolding of the story, so that the learner is presented with input to their storification process but can only exercise control over it by attending or not to this input. Empathic identification with the story-teller or the characters may allow the learner to experience the events of the story at second-hand, and to this extent it can support experiential learning.

The second approach is that of story authoring, in which learners themselves create the story, in either of the two variants just discussed. Varying degrees of freedom may be given to this authoring process, either by controlling the components (characters, events) to be used, the initial situation in which those components stand at the start of the story, the story genre (a fairy story, an adventure a soap-opera, an epic), or through the existence of multiple authors who must collaborate. The role of the learner is the converse of that in the first approach since they are required to choose between possible options, structure events, decide upon characters and their behaviour.

In the first-person variant (telling) an author may have to construct a narrating persona, but where digital authoring is used, more often the computer itself becomes the actual narrator. This removes the issue of expressive behaviour, neutralises the issue of trust (the computer is considered inherently authoritative), 
and prioritises actions, and their structuring into plot over character: the dominant medium is necessarily language with other digital materials acting as illustrations. The third-person variant requires more support in terms of digital materials since the author must be able to define characters - virtual actors - who will present the story (showing). Language still plays a central role, though now in the form of dialogue, but the visual aspects of story presentation may also be important, with the mechanisms of film and television often applied. We will consider systems supporting both approaches in a later section.

Where storytelling relies entirely on input to the storification process, authoring outputs from the internal storification into the authored experience, whether told or shown, though this may in turn feed back into the continuing storification process. The active engagement with story required by authoring is clearly very much in tune with a constructivist approach to learning.

However both story-telling and authoring have in common the roles of author and spectator; the difference from the learner perspective is which of these they are asked to play. The third approach, of story participation, is entirely different in this respect. It is an essentially improvisational approach in which the learner becomes a character in a role-play, and the distinction between author and spectator vanishes into a simultaneously created and experienced story that is also inherently collaborative with the other characters. It is true that authoring also allows the user to move between creating and considering their story, but in participatory storycreation the god-like control of the author is lost and the story becomes a process which cannot be halted at will. Participation is also a totally different experience from spectating, since the commitment to act (having to decide what to do next) and the necessarily partial perspective of a specific character radically change the input to the storification process. In turn the actions carried out in role change the story world and impact other characters, producing a tight circular flow between the internal process and the state of the story-world.

While the first two approaches have been considered in narrative theory since Aristotle (330BC), this third approach is largely undiscussed by narratologists, though as an activity it has moved from its origins in theatre into educational roleplay, desk-top and live-role play games, as well as into multi-player online roleplaying games, with an associated practitioner literature (some examples). In digital form it is problematic, for reasons that will be discussed later, but is in some sense a 'holy grail' since it would allow the development of truly interactive narrative experiences.

\section{SUGAR ON THE PILL?}

We have seen, then, that story is a powerful mechanism of great relevance to learning and that it has been widely applied in many different fields of learning. It is interesting to consider to what extent the ways in which story has been applied generally in education have been taken up in computer-based systems. In other words, do we actually have digital narrative learning environments? 


\section{RUTH AYLETT}

In considering this question it is important to recall the definitions of story given above. We argued for a definition based on the dynamic interaction between character and causation, so that a narrative learning environment would be one in which this dynamic served an educational purpose in any of the three forms of story-telling, authoring or role-playing.

\section{Story-telling}

It is not too difficult to find examples of story-telling in educational applications. For example, the Not So Naughty Stories CD-Rom (The Not So Naughty Series, 2005) contains a collection of stories about 'naughty' characters aimed at teaching the consequences of bad behaviour and how such behaviour affects others. Each story is supported by three reinforcing interactive activities which aim to encourage pupils to think about and discuss the PSE themes covered. However these stories are not so different from the book-based equivalent, except for the use of media such as video clips or animations; but this in turn is little different from a television or video presentation: individual control over the pace of story presentation is the main addition. This does not seem to deserve the specific name of a narrative learning environment.

A step in the direction of interactivity is sometimes made in the form of a branching narrative, in which specific choices are offered at particular choice points, in the style of the 'adventure books' popular in the 1980s where at the end of a short episode the reader was asked to turn one of a small (three usually) set of specific pages. The development of hypermedia made this a popular option since it became very easy to implement, but even a modest branching factor complicates the authoring task to a noticeable extent unless frequent branching back into the main sequence takes place, and this can soon become noticeable to the learner as a lack of any real control over the direction of the story. Worse than this, the learner may come to feel that since there is a 'correct' path through the story they should interact with the meta-story world of the pedagogy and guess where this is, so that the ability to suspend disbelief in the story world is lost.

A branching approach also has clear implications for any other actors in the story who offer too few interactional options to make them other than vehicles for the plot. The participation of the user can thus in some sense be seen as motivational sugar on the pill of the author's intended sequence.

The use of story for motivation is widely seen in games-based educational software. The graphical adventure game is the model for these packages, with Granny's Garden, dating back to 1983 (Granny's Garden, 2005), a classic of this type in the UK. These are interactionally open but at the expense of any real integration of the story into the problem-solving activities that are the pedagogical focus. Granny's Garden is set in the Kingdom of the Mountains: the King and Queen of the mountains have been imprisoned in a secret cave and their children hidden in four strange locations, with the aim set the learner of finding them. The search involves simple tasks to perform and puzzles to solve. For example, four young dragons must be tamed, or a helper creature must be selected. The 
educational objectives relate to the UK National Curriculum attainment targets in speaking and listening, reading and ICT.

In considering this type of software as a specifically narrative learning environment, it becomes important to consider just how far an adventure game is a narrative form. We argue that in general it is not: although characters may be involved in the problem-solving tasks, there is seldom any real integration between characters and causation outside of a single activity. A character is usually either a mobile source of information supporting a problem-solving activity, or in some cases a decorative part of a puzzle. Back-story is thus used to justify the inclusion of the tasks and puzzles and motivate the final goal of the adventure but plays no integral role in the activity of the learner. Where sequencing of activity is important, it relates to the logical order in which puzzles must be solved and not to character development or dramatic trajectory. The ability to return to earlier saved states of the puzzle-solving activity further reduces the impact of any story elements since causation is never final.

Thus in the Logical Journey of the Zoombinis (Logical Journey of the Zoombinis, 2005) the back-story provides the reason why the Zoombinis must be shepherded to a new home but the logical puzzles to be solved en route are not themselves part of a coherent story. For example the Pizza Eating Trolls motivate an exercise in constraint-based logical inferencing since a particular combination of pizza toppings is required by a troll to allow one Zoombini through the village. Though this is a more colourful clothing of the problem than the men with ladders and baths of traditional applied mathematics, the role played is in fact no closer than these to narrative. Games and stories may overlap in this way but they are not the same thing: games involve solving puzzles, scoring points and winning and the player can often start again and again. Stories involve action sequences, character development, emotional trajectories: what has happened is in the past is not rerun.

The superficial role played by narrative in such applications is demonstrated by the falling away of the approach with older children. The more critical stance of older learners makes it easy for them to penetrate the narrative camouflage to the educational intent, with the risk that they will perceive this use of story as somewhat patronising. With adolescents, there is a clear move towards simulation, with the interaction between the choices of the learner and the rules of the simulation driving the learning process. This is in some sense a half-way house between authoring and spectating, with the interventions of the learner from a godlike authorial perspective rendered less predictable by the responses generated by the simulation rules.

A good recent example of this genre is Real Lives (Real Lives, 2005), a simulation allowing students aged 13-17 to explore the path of a personal life and social context for a randomly generated individual, using statistics to determine the character's socio-economic, cultural, and religious background, as well as their initial health and likelihood for survival. Students can explore information about the character's country, family, and life, ranging from politics and religion, to access to health care and clean drinking water. 


\section{RUTH AYLETT}

When the simulation is advanced one year in the character's life, new choices become available; initially merely how to spend free time, but each choice shapes the character's future. Decisions to help others influence the character's conscience score, while decisions to start relationships or have a family affect happiness, as does the balance between a character's work and leisure activities. A decision early in life to accept alcohol, cigarettes, or drugs can result in health problems for the character later. Choosing to have the character become politically or socially active can result in job loss, expulsion from school, imprisonment, and even torture, depending on the character's native country. The simulation can itself add events such as natural disaster or health problem, acts of violence or peer pressure.

However, like most simulations, the focus of Real Lives is on decision-making not on story-creation, and its outputs are textual reports and statistics. The affective impact of events like death, disaster and ill-health is not part of the simulation. In general, the schematic representation of character and the necessarily compressed timescales of simulations exclude the kind of multiple character interaction required for a convincing narrative experience. Just as with adventure games, it is hard to see a simulation environment of this type as an NLE.

\section{Story-authoring}

Story-authoring is able to avoid a clash between interaction and authorial control because the learner has the authorial control and interaction is put at its service. Story creation is seen as the key pedagogical process, though learning objectives may be various, from better use of language, understanding character motivations and actions by extending existing stories or putting existing characters in new stories, to the thinking through of decisions without the guiding hand of a simulation.

Authoring is of course widely used in learning, but its use for digital story construction has not in many cases progressed much beyond a word processor and some associated work sheets. The availability of generic multi-media authoring tools such as Director has been exploited but few commercially available packages offer much higher level support for an authoring process in which the story is not primarily textual.

An exception is Kar2ouche (Kar2ouche, 2005) in the UK - a 2D story-boarding package, it is sold with specific materials for a number of different topics, from bullying to Shakespeare. Each variant is sold with a gallery of $2 \mathrm{D}$ characters who can be posed by the author against one of the provided backgrounds or against new backgrounds imported by the author. A 'speech bubble' facility allows typed text to be associated with a character and recorded speech can be added as well as background sound effects. Once authored, the story board can be run as a slide show via conversion to mpeg. Thus a learner can author a story and then present it to an audience, though the presentation is not of course interactive.

The most interesting generic commercial packages for story-authoring may well be games engines. For example, the game Never-Winter Nights (Gorniak \& Roy, 
2005) also includes authoring facilities that allow adventure games to be constructed by a learner. The advantage of using a games engine like this is that the very professional $3 \mathrm{D}$ graphics and animation allows the author to produce a visually attractive story quite rapidly. The disadvantages lie in the assumptions about the type of activity that is to be authored built-in to any games engine. We have argued above that an adventure game is not a narrative form in and of itself: In Never-Winter Nights it is easy to produce 'stories' that involve puzzles associated with objects, finding treasure, fighting monsters and pre-scripted interaction with characters. However it is not aimed at creating complex characters or at allowing more than a small fixed number of decision branches for the user of a character. If one would wish to define a NLE as something that not only supports authoring but also a participative narrative experience for the learner in a variety of genres then no NLE is yet commercially available.

\section{Stories and interactivity}

The difficulty of producing an integration of causation and character seen in the examples cited above is very much a product of the need to incorporate interactivity given it is a fundamental distinguishing characteristic of digital media. However, as we have seen, this is not at all easy. On the one hand, the medium offers the learner the potential freedom to go where they want and interact with whatever interests them. On the other, a pre-determined narrative plot specifies where they should go when and what they should do in each stage of the unfolding of the plot. There is a fundamental conflict between interactional freedom and the structuring requirements of plot that we have termed the narrative paradox (Aylett $\&$ Louchart, 2003). Film and television, though representationally similar, in fact otherwise have very different presentation characteristics, as seen in Table 1:

Table 1: Presentation characteristics of media

\begin{tabular}{|c|c|c|c|c|}
\hline & Cinema & Theatre & Literature & $\begin{array}{l}\text { Digital } \\
\text { graphical }\end{array}$ \\
\hline Contingency & Low & Medium & Low & High \\
\hline Representation & Visual & Visual & Textual & Visual \\
\hline Presence & Not physical & Physical & Not physical & Immersive \\
\hline Story control & Very high & Medium & Complete & Low \\
\hline Interactivity & No & Some forms & No & Yes \\
\hline
\end{tabular}

By contingency, we mean the extent to which the story happens 'in real time'. Film can play very flexibly with time, using slow motion, dream sequences and flash backs amongst other techniques: theatre tends to run in real time on stage with time passing between scenes and acts, Literature is the most flexible of all in this respect, while in digital graphical environments in which the learner participates, it is hard not to run on the learner's own subjective clock. Contingency is also related to whether the learner is or is not physically co-located with the characters: clearly 
not the case in film or literature, but true for on-stage activity in the theatre in which the audience is co-located with the performers. In Digital Graphical media, the learner may at least be virtually present, in the sense of sensory immersion within the scene itself, rather than around it as in most theatre. The degree of story control can be seen as related to some of these features: the lack of presence of either actors or spectators in film at presentation time gives the director a very high level of control indeed, down if necessary to the expression on an actor's face, though not quite as high as in literature where only the author's chosen words appear in the story. In theatre, a script and rehearsals exercise some control over actors but the real-time nature of the unfolding of the narrative allows the actors some dynamic control, including ad-libbing of dialogue or varying of stage directions as well as the more obvious control over their own expressive behaviour. In fact we argue that the element of real-time interactivity in theatre makes it closer to Digital Graphical environments than is film, especially in theatrical forms in which audience participation is involved and character improvisation is employed.

The applications cited above deal with the conflict between story-control and interaction in a number of well-understood ways. Game-based systems allow interactional freedom but largely abandon narrative structuring. Simulations focus on causation rather than character and limit the interactional freedom of the learner, pushing their role in the direction of authoring. Authoring systems avoid the problem by tackling authoring rather than narrative unfolding.

We suggested above that story results from a tight integration of causality and character. A common deficiency in most of the systems we have mentioned and in very many more is a weak conception of character. In particular, digital characters seldom have any autonomy, that is, the ability to select from a repertoire of actions according to input to their own sensors of key facts about the state of the environment, whether user actions, exogenous change in the environment, or the actions of other characters. Combine this with a lack of any memory for previous interactions and a character becomes incapable of more than one-shot interaction and with the user only, not each other. In addition, characters lack expressive behaviour which would support a suspension of disbelief by the learner and make them 'feel' like real characters with their own inner life. Such characters cannot become a source of story.

\section{CHARACTERS AND STORY}

Current research into learning environments in which narrative is a central part of the learning experience has focused heavily on the character deficit just referred to. Adding autonomy is one clear research direction - another closely related one is the integration of emotional systems into intelligent character architectures so that emotionally expressive behaviour can be generated. 
AND THEY BOTH LIVED HAPPILY EVER AFTER?

\section{Creating autonomous characters}

A character can only act autonomously if it receives information from the environment in which it is located so that it can respond by selecting an appropriate action from its repertoire. Top-down scripting, often the chosen mechanism in computer games characters, cannot produce the flexibility and responsiveness that is required. These are issues that have been discussed over many years in robotics, and indeed one can think of an autonomous graphical character as a robot with a much simpler world, the ability to sense without error and ambiguity, and to act without the danger of falling over or running out of battery power. Thus it should come as no surprise that work in graphical autonomous characters has drawn heavily on work in robotics. Researchers have tended to follow either the more cognitive architecture route of earlier robotics (Nilsson 1984) for human characters, incorporating a planner, or the reactive behavioural approach pioneered by Brooks and others (Brooks, 1991) from the mid 1980s for animal-based characters.

Behavioural architectures have been used for many attractive 'computer pets', of which Dogz, Catz and Babyz were good commercial examples (Petz, 2005). Some interesting interactive installations involving animal characters have also been created by researchers - for example dog clicker training (Burke \& Blumberg, 2002), AlphaWolves (Tomlinson et al, 2002) and Blumberg's original Silas.T.Dog (Blumberg, 1996). While animal characters with this type of architecture can certainly be used for education (see Tomlinson et al, 2005 for a good example) it is much less clear that they can form more than a partial element in a narrative learning environment without long-term goals or the ability to plan sequences of actions. The PUPPET project (Marshall et al, 2002) built a reactively-driven (but cultured!) cow in persistent conflict with an authoritarian farmer and supported learner interaction via having them role-play a sheep within the scenario: it showed that while an engaging experience could be created, its structure was too cyclical and repetitive to be perceived as a story.

Autonomous human characters require the ability to sequence their actions over time, including language-based actions, if they are to seem believable for interactions more complex than fights. Thus AI planning technology, usually derived from the class STRIPS planner (Fikes \& Nilsson, 1971) is seen as a vital component of these more cognitively oriented architectures. A straightforward use of this technology involves authoring 'plan trees' - a branching structure for each character in which different actions are executed depending on certain conditions in the live environment. This can be seen as a half-way house between linear scripting and a generative planner which creates actions 'on the fly'; the approach was used by (Cavazza et al, 2002) to create short stories around characters based on the US soap opera Friends. By starting characters in different locations their interactions occurred at different times and different stories resulted. The user did not play a character in the scenario, but rather influenced what happened through the ability to move significant objects (such as a diary that one character wanted to 
check for information) forcing the characters down different parts of their branching plan-tree.

This approach might be thought of as a variant on what researchers had termed 'universal plans' (Schoppers, 1987) - the idea that all possible actions in all possible combinations might be represented in a data-structure created off-line and merely traversed at run-time by a character. However a criticism originally raised against Schopper's work still stands in relation to modern reuse of this idea: while it works for small scenes it is liable to a combinatorial explosion over a larger drama and poses an almost intractable authoring problem.

The size of the authoring problem is demonstrated by Façade (Mateus \& Stern, 2002), a downloadable interactive drama in which the user spends a virtual evening with two characters, Grace and ??, who, it emerges, are in a destructive relationship similar to that in the drama 'Who's afraid of Virginia Wolf?'. The underlying dramatic structure is organised around a concept of beats, or small pieces of dramatic structure, each of which can be invoked by a specific piece of character and user interaction. The released version is said to contain something like 20,000 of these for a 20 minute drama: the realisation is very engaging and elegant but the authoring effort has taken several years.

\section{Creating expressive and believable characters}

A number of research groups have focused on developing characters in which a model of emotion supports expressive behaviour, on the grounds that characters can only convince if they appear affectively engaged with their environments and with a human participant. The researchers at the University of Southern California - USC - and the related Institute for Creative Technologies - ICT - have created a number of educational or training systems in which affectively driven characters are used to create a specifically narrative learning environment.

The Mission Rehearsal Environment (MRE) (Marsella et al, 2000) looks at training soldiers in peace-keeping. In the scenario reported in the literature, the trainee turns a virtual corner in a virtual jeep to find that one of his unit's vehicles has run over a local child. Distant explosions and radio messages remind him that he is supposed to be assisting comrades under fire elsewhere; his medical officer advises that the child must be airlifted for urgent medical attention, the child's mother becomes increasingly emotional about the situation and a sergeant acts as a tutorial figure assisting him to make decisions about what to do. Further emotional pressure is applied by a crowd of onlookers.

The key character development in this scenario is that of the mother: autonomously driven by an architecture including an integrated affective appraisal system based on the ideas of Ortony, Clore and Collins (1988) - the OCC model and the coping behaviour model of Lazarus (Lazarus \& Folkman, 1984). Initially crouched over her injured child, if a medical evacuation is not ordered she becomes angry and starts standing up and shouting. The onlookers are scripted characters who reinforce the sense of urgency and pressure, while the autonomous sergeant implements a planning-based tutorial system used in earlier work. The narrative is 
short and is in fact driven by a simple branching structure, but the expressive behaviour displayed by characters and the sense that they are responding to the trainee's decisions produces the feeling of character and causation interlocking in a narrative structure.

A second interesting educational system developed by some of the same researchers (Gratch \& Marsella, 2001) is Carmen's Bright IDEAS. This is a system intended to educate the mothers of young cancer patients in a cognitive behavioural therapy approach to dealing with the multiple problems they often experience fear for their child, problems with other family members, work and financial problems. It takes the form of a dramatic segment illustrating one of these problems for a character called Carmen, as a piece of scripted multi-media, followed by a dialogue between Carmen and a psychiatrist called Gina. In this dialogue, Carmen is driven by an autonomous architecture with an affective component, while Gina plays a tutorial role. Unlike the MRE, the user does not play a direct role, but is allowed at intervals to select one of three 'thought bubbles' appearing over Carmen's head which drive her behaviour in a particular direction. Again, this produces a finite branching structure, but as in the MRE the believable nature of the characters (reinforced in this case by a database of speech utterances recorded by actors) engages the user in the character interaction.

Carmen's Bright IDEAS is very much dialogue based by comparison with MRE and with other systems discussed in this section, and the framework of a therapeutic session is not inherently narrative. However the emotionallydemanding nature of the framing story - a child ill with cancer - as well as the ability of the users to identify with Carmen's problems from their own lives, again gives the system a narrative feel. Though initially developed as a research system, this has since gone into clinical trials, and the educational impact has been assessed very positively with its intended users (Marsella et al, 2003).

\section{Drama or real life?}

An issue of great concern to many researchers in this field, and also potentially very significant from an educational point of view, is whether a narrative learning environment aims at realism and a more documentary style, or whether it is based on the conventions of fiction and especially of drama. In terms of the media discussed earlier, this may be seen as a question of whether classic film - which is typically though not inevitably naturalistic - is the main model, or whether cartoons and theatre are more useful sources of inspiration.

Much graphical research has gone into the development of graphical photorealism, with recent hardware able to demonstrate very high-quality visual results even on quite reasonably priced desk-top systems. An implicit assumption behind the striving for photo-realism for graphical characters is that a more naturalistic character must also be a more believable one. It is not easy to define believability (Bates 94) but it is usually taken to refer to characters perceived by the user as compelling and engaging, for which they are willing to suspend their disbelief and which they treat as if they had an independent inner life. It is then clear from the 


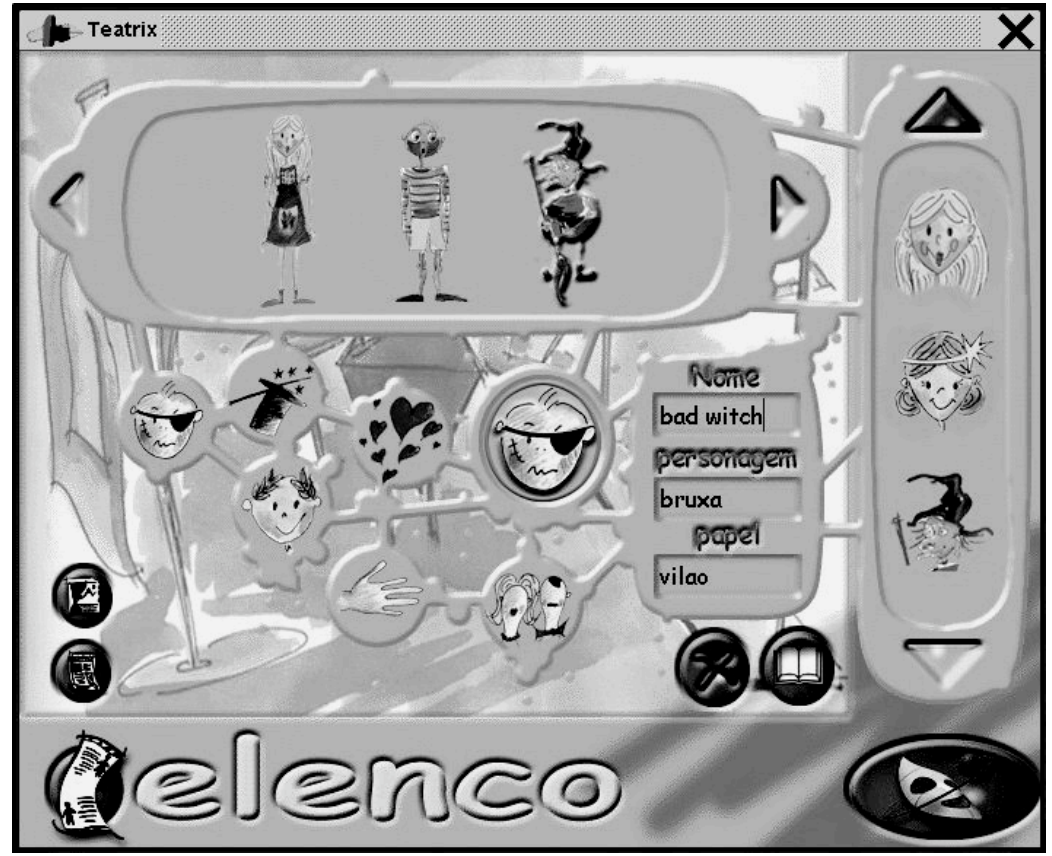

Figure 1: TEATRIX character and role choice

history of cartoon animation that believability does not in fact require naturalism Mickey Mouse, probably the most successful animated character ever, looks nothing like a real mouse. Moreover a comparison between the animated films "Toy Story" and "Final Fantasy" demonstrates that in some cases a non-naturalistic character can be more believable than a naturalistic one - certainly Buzz Lightyear in the former has made a far greater impact than any of the characters in the latter.

It seems this is no accident: seminal work by Mori (Mori, 1982) in relation to robots, discussed in (Dautenhahn, 2002) in the context of the 'life-like agents hypothesis', suggests that more naturalistic characters can be quite problematic for user engagement. Mori predicted that the more life-like a robot became, that is, the more naturalistically human, the more familiar it would also become. However, he argues that just short of $100 \%$ naturalism, there is actually a sharp drop in familiarity - or we might now say believability; a drop so deep that it forms what he calls 'the uncanny valley'. An explanation of this effect suggests that a nearlynaturalistic character is capable of invoking standard human-to-human responses up to the point where these heightened expectations are jolted by some minor inconsistency. This jolt is experienced as a highly negative reaction. Believability then seems partly to depend on consistency between the expectations of the user and both the attributes and behaviour of the character.

Neither MRE nor Carmen's Bright IDEAS aim at photo-realism, though MRE does use recognizable $3 \mathrm{D}$ characters and heightens its $3 \mathrm{D}$ graphical environment 
with a very convincing sound track of explosions and helicopter engine noise. Carmen's Bright IDEAS was implemented in 2D in a much more cartoon-like style, with for example little attempt at synchronizing the character's lip movements with its speech output. Again, the sound track is more naturalistic than the visuals, with the use of recorded human voices containing strong emotions.

Two final examples of research-based NLEs both openly use drama and more cartoon-like characters in order to avoid raising user expectations that cannot then be met. TEATRIX (Machado et al, 2001) takes the structural narrative analysis of Propp (1928) as the basis for a fairy-story-based narrative environment aimed at a collective authoring experience for children which is later used as material for individual creative writing. Propp had used a corpus of Russian fairy stories to derive a common set of roles and abstract actions. TEATRIX allows children to choose a character, for example a wolf, witch, girl, or boy, and then a role: hero, villain, helper etc (see Figure 1 above). Some characters are played by children and some by autonomous characters with an affective architecture in a set of locations selected by the learners from the given repertoire, linked together, and populated with various objects.

A particular innovation of TEATRIX was its encouragement of reflection on story incidents through 'hot seating' - breaks in the action in which the motivations of characters are explored (see Figure 2), a concept taken from the Brazilian dramatist Boal's Forum Theatre (Boal, 1979). This was introduced after it was observed that children would get so immersed in the action that they did not consider character motivations, so that their later reworking of the experience in

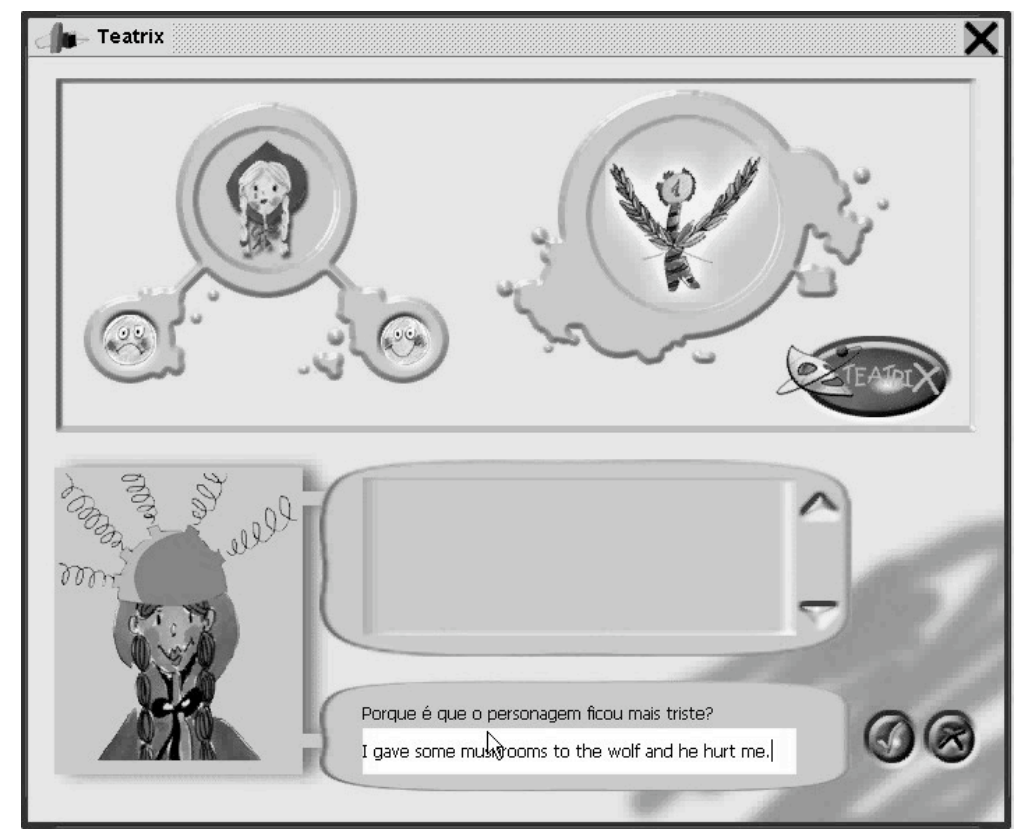

Figure 2: TEATRIX "Hot Seating" 


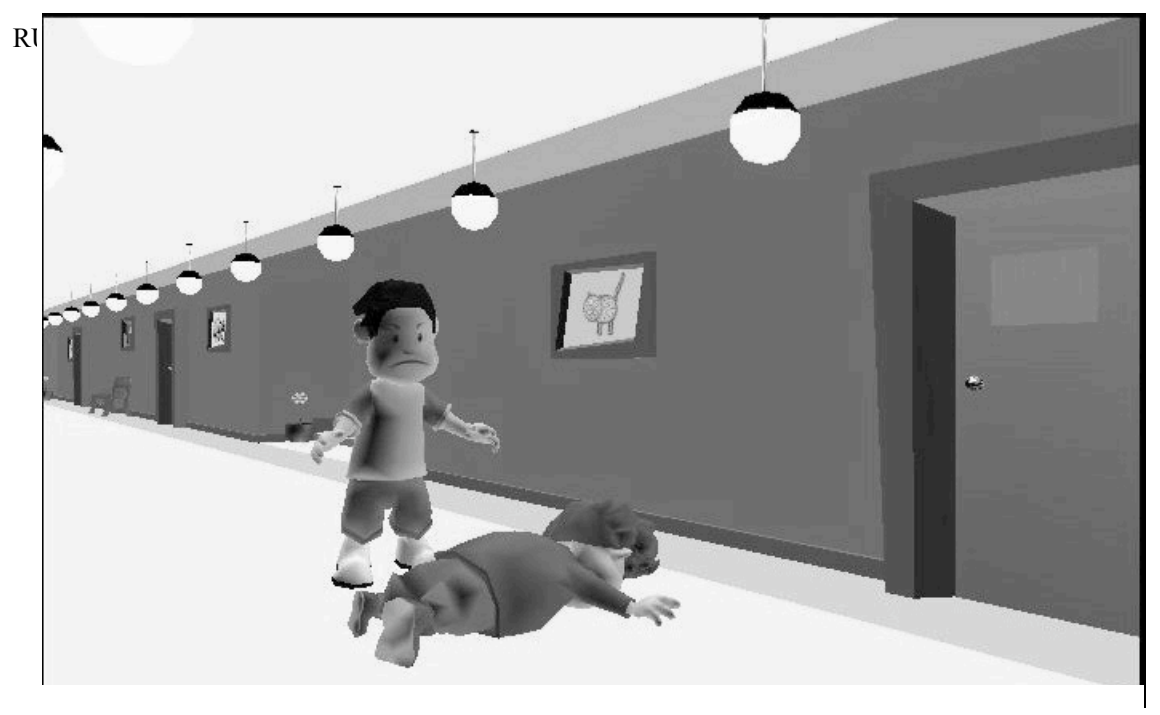

Figure3: A character in FEARNOT! being bullied

individual creative writing was a sequence of events with little or no characterization. This oscillation between story action and meta-story reflection is very like collective children's play, while the authoring focus allows the system to avoid the clash between narrative structure and user freedom already discussed.

FearNot! (Aylett et al, 2005) takes a more ambitious approach to solving this narrative paradox, though it too has been heavily influenced by Boal's dramatic approach. Aimed at education against bullying, it uses 3D virtual characters in a virtual school and asks the child user to act as the 'invisible friend' of the victimised character.

A short episode in which the character is bullied (Figure 3) is followed by interaction in which the child is asked for advice (Figure 4): this advice then influences the actions of the character in the following episode. The episodes are not pre-scripted but are generated by interaction between the characters, who have an affective appraisal system and autonomous action-selection capabilities, producing an emergent narrative. The pedagogical effect is based on the idea that empathy between the child user and the victimised character can be developed so that the child really cares what happens: evaluation has shown that this does indeed happen (Hall et al, 2005).

\section{WHAT'S NEXT?}

Earlier in this chapter we argued that there is very little - if anything commercially available that really justifies the title of Narrative Learning Environment. However the research systems we have discussed in the previous section show that NLEs are now more than a mere concept. Taking some of the innovative ideas and systems from research prototypes through to delivered 


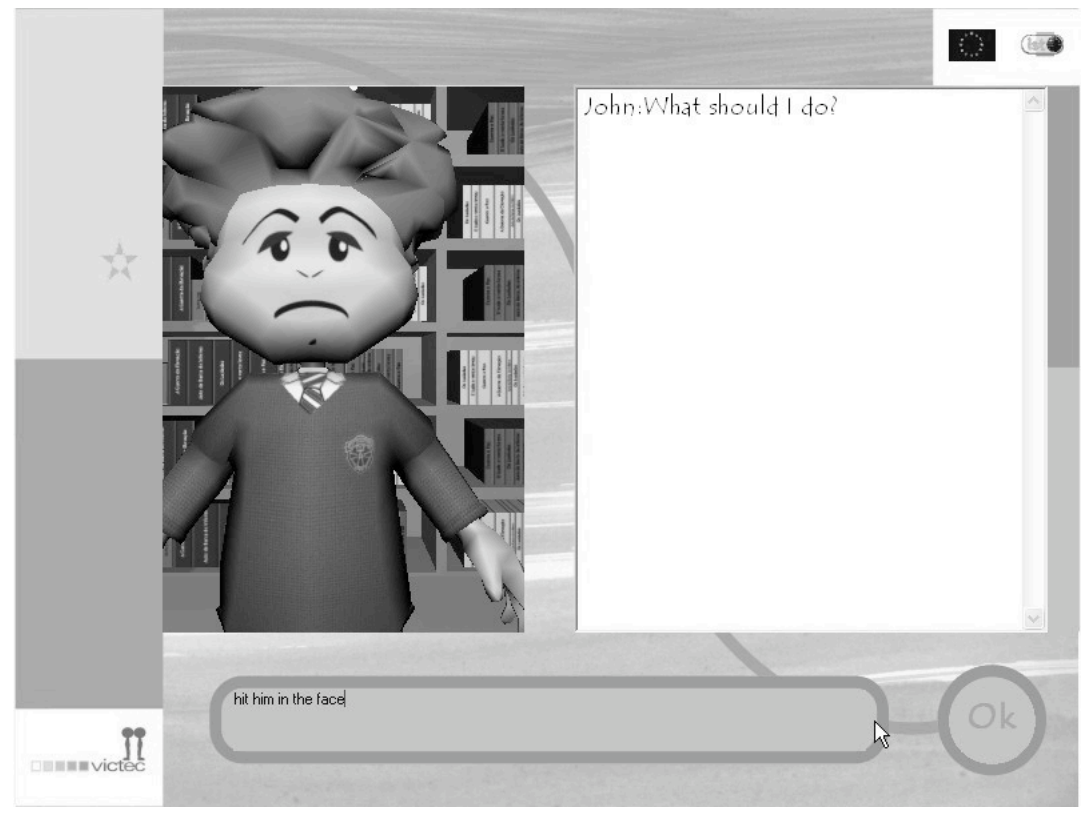

Figure 4: A child advises the bullied character in FearNot!

systems is what is needed in order to make NLEs a real educational option. This is of course non-trivial since it depends not only on the maturity of the technology but also on the business case convincing educational software producers to move in this direction.

One issue is that there is little in the way of generic tools that could help software suppliers to take research outputs on board. We have argued that a key factor in making narrative a central part of an educational application rather than a motivational sugar is the development of rich autonomous characters with expressive behaviour and affective internal state. There is to date no toolkit that would assist the development of such characters, especially given the close links they require between graphical tools specifying the character body and animation behaviours and the AI tools required to specify personality and internal affective parameters.

This requirement for both AI and graphics capabilities is one reason why the most obvious toolkits - those supplied with various games engines - have their limitations, quite apart from the licensing issues arising from their proprietary nature. Typically they take a graphics perspective in which Non-Player Characters (NPCs) are moved around by a global control mechanism and in which the entire internal state of the game is used as substitute for local sensing, producing NPCs that can 'see round corners' and lack believable constraints on their sensing capabilities. On the other hand, given the high quality of graphical presentation in computer games, it is now a very difficult attribute on which to compete, so that 'better AI' is now being mentioned by a number of games as their selling point. 
As against this hopeful development, games companies currently seem very conservative in the development of new genres, with a tendency to updated versions of existing successes rather then the exploitation of autonomous character technology in order to develop new ones. As a result the narrative aspects of games are nearly universally absent or extremely weak. This conservatism and the baggage that comes with the existing genres needs to be considered very carefully before assuming that 'games-based' education is necessarily always a step forward.

A very interesting technological development in relation to NLEs is the use of mobile and 'mixed reality' technologies, in which rather than locating the NLE entirely inside a desktop computer, it is taken out into the real world. An example of an educational application using this approach is the Virtual Savannah (Facer et al, 2004), implemented at a school in Bristol, in the UK, in which the virtual savannah was mapped onto the school playing fields along with a pride of virtual lions and some virtual antelope. Children carried out the educational work with a PDA on the playing field and were able to explore some of the aspects of lion life through virtual 'marking of territory' and hunting of virtual antelope using the PDA as a guide to the location of the virtual world within the real one.

An example of the way in which this technology might be used within something like a story framework can be seen in an artistic game experience, 'Uncle Roy All Around You', (Uncle Roy All Around You, 2005) authored by Blast Theory and run in a number of UK cities in 2004 and 2005 (ref). In a onehour experience, users were given a PDA and set a number of tasks concerned with finding 'Uncle Roy' out in the real city. A number of other users were given desktop virtual environments mapping the real world in which the PDA-equipped users moved and were able to follow the progress that they made since the mobile users were told they would receive hints if they phoned in and reported their position.

An interesting aspect of the hints given to mobile users was that they might be told 'watch for an approaching tourist' when no such person was actually provided by the organisers. Thus complete strangers could be incorporated into the story by drawing on the imagination of the mobile user if it happened that someone did by chance approach at the relevant moment. In the terminology of section above, the organisers were feeding the storification process of the mobile user.

The incorporation of actors in this process in some sense validates the point made here about the importance of compelling characters to a sense of story. One could think of this as augmented role-play, and see a combination of role-play by real characters with extra virtual characters as a route to an NLE in which the real, the virtual and the imagined all combine.

\section{CONCLUSIONS}

In this chapter we have tried to examine the relationship between story and learning and the extent to which digital technologies currently do or could support NLEs. The importance of story to learning and the role it has played in nondigitally supported learning has been considered. We have argued strongly that it is 
not the case that any use of story in digital materials necessarily results in a narrative learning environment, if by this we mean one in which story is an integral part of the learning process rather than an attempt to motivate the learner or make drill exercises superficially less dry. We have also looked at the role of story in computer games and have discussed some of the problems arising from the clash between interactivity and narrative structure as well as some of the ways that this conflict has been addressed. The addition of believable - and autonomous characters - has been identified as a key area for the development of NLEs and a number of interesting research systems have been cited as evidence for the feasibility of NLEs. Finally we have considered where progress must be made if NLEs are to become a widely available resource for educators.

\section{REFERENCES}

Aristotle. 330 B.C. The Poetics of Aristotle, translation and commentary by Stephen Halliwell. Duckworth, 1987

Aylett, R.S. (2000) Emergent Narrative, Social Immersion and "Storification" Proceedings, Narrative Interaction for Learning Environments, Edinburgh, 2000.

Aylett, R. S., \& Louchart, S. (2003). Towards a narrative theory of virtual reality. Virtual Reality , 7, 29.

Aylett, R. S., Paiva, A., Woods, S., Hall, L., \& Zoll, C. (2005). Expressive Characters in Anti-Bullying Education. In L. Canamero \& R. Aylett (Eds.), Animating Expressive Characters for Social Interaction: John Benjamins.

Bates, J. (1994). The Role of Emotion in Believable Agents. Communications of the ACM, 37(7) \&P 122-125.

Bednar, A.K., Cunningham, D., Duffy, T.M., and Perry, J.D. (1991). Theory into practice: How do we link? In G. Anglin (Ed.), Instructional Technology: Past, Present and Future. Englewood, CO: Libraries Unlimited, Inc.

Blumberg, B. M. (1996). Old Tricks, New Dogs: Ethology and Interactive Creatures. PhD thesis, Media Lab . Cambridge, MIT

Boal, A. (1979). Theatre of the Oppressed. New York: Theatre Communications Group.

Brookfield, S. (1990). The Skillful Teacher. San Francisco.: Jossey-Bass Publishers.

Brooks, R. A (1991) Intelligence Without Reason, Proceedings International Joint Conference on Artificial Intelligence (IJCAI 91), Morgan Kaufmann, pp 569-595.

Bruner, J. (1987). Life as narrative. Social Research, 54, 11-32

Burke, R.C and Blumberg, B (2002) Using an Ethologically-Inspired Model to Learn Apparent Temporal Causality for Planning in Synthetic Creatures Joint Conference on Autonomous Agents and Multiagent Systems, AAMAS 2002. July 15-19, 2002

Cavazza, M; Charles, F; Mead, S.J (2002): Character-Based Interactive Storytelling. IEEE Intelligent Systems 17(4): 17-24

Dautenhahn, K. (2002) The Design Space of Life-Like Robots. Proc. 5th German Workshop on Artificial Life, Lübeck 18th - 20th March, 2002, IOS Press, Eds D. Polani, J. Kim, T. Martinetz, pp. $135-142$

Davison, J., \& Arthur, J. (2003). Active Citizenship and the Development of Social Literacy: a case for experiential learning. Canterbury: Citizenship and Teacher Education.

Edwards, D. (1997). Discourse and cognition. London: Sage

Facer,K; Stanton,D; Joiner,R; Reid,J; Hull.R \& Kirk,D. (2004) Savannah: Mobile Gaming and Learning? Journal of Computer Assisted Learning, Vol 20, pp399-409 


\section{RUTH AYLETT}

Fikes, R; Nilsson, N.J (1971): STRIPS: A New Approach to the Application of Theorem Proving to Problem Solving. IJCAI 1971: 608-620

Gergen, K.J. (1994) Realities and relationships. Cambridge: Harvard University Press.

Gorniak, P \& Roy, D (2005) Speaking with your Sidekick: Understanding Situated Speech in Computer Role Playing Games Proceedings of Artificial Intelligence and Interactive Digital Entertainment, 2005

Granny's Garden (2005) http://www.simonmidgley.co.uk/software/adventure/granny.htm accessed Oct 2005

Gratch, J., \& Marsella, S. (2001). Tears and fears: Modeling emotions and emotional behaviors in synthetic agents. Paper presented at the Fifth International Conference on Autonomous Agents.

Hall, L., Woods, S., \& Dautenhahn, K. (2004), FearNot! Designing in the Classroom. Paper presented at the British HCI, Leeds, UK.

Henriksen. (2004). On the Transmutation of Educational Role-Play: a critical reframing to the Role-Play to Meet the Educational Demands. In M. Montola \& J. Stenros (Eds.), Beyond Role and Play Tools, Toys and Theory for Harnessing the Imagination (pp. 107-130). Helsinki

Kar2ouche (2005) http://www.immersiveeducation.com/uk/Kar2ouche JISC.asp accessed Oct 2005

Kolb, D. A. (1984). Experiential Learning : Experience As the Source of Learning and Development: Prentice-Hall.

Lazarus, R.S\& Folkman, S. (1984). Stress, appraisal and coping. New York: Springer

Lewin, K. (1951). Field Theory in Social Science. New York: Harper and Row.

Linser, R., Naidu, S., \& Ip, A. (1999). Pedagogical Foundations of Web-based Simulations in Political Science. Paper presented at the ASCILITE, University of Wollongong, Wollongong, NSW, Australia.

Logical Journey of the Zoombinis (2005) http://www.superkids.com/aweb/pages/reviews/math2/logical/merge.shtml accessed Oct 2005

Machado, I., Paiva, A., \& Prada, R. (2001, May 28 - June 01). Is the wolf angry or just hungry? Inspecting, modifying and sharing character's minds. Paper presented at the 5th International Conference on Autonomous Agents, Montreal, Canada.

Marsella, S., Johnson, W. L., \& LaBore, C. (2000). Interactive Pedagogical Drama. Paper presented at the 4th International Conference on Autonomous Agents

Marsella, S., Johnson,W.L. \& LaBore, C (2003) Interactive Pedagogical Drama for Health Interventions. In 11th International Conference on Artificial Intelligence in Education, Australia, 2003

Marshall,P; Rogers, Y and Scaife, M (2002) PUPPET: a virtual environment for children to act and direct interactive narratives. 2nd International Workshop on Narrative and Interactive Learning Environments, (Edinburgh, 2002).

Mateas,M; Stern, A (2002): A Behavior Language for Story-Based Believable Agents. IEEE Intelligent Systems 17(4): 39-47 (2002)

Montemayor, J., Druin, A., \& Hendler, J. (2000). PETS: A Personal Electronic Teller of Stories. In A Druin \& J. Hendler (Eds.), Robots for Kids: New Technologies for Learning. San Francisco, CA: Morgan Kaufmann.

Mori, M. (1982), The Buddha in the Robot, Charles E. Tuttle Co

Nilsson, N.J. (1984), ed., Shakey the Robot, SRI Technical Note no. 323, SRI, Menlo Park, California.

The Not So Naughty Series from Sherston Publishing. .Suitable for: Age 5-7 / KS 1 / Scottish P1-3. See http://www.rm.com accessed Oct 2005

Ortony, A; Clore, G., and Collins, A. (1988) The Cognitive Structure of Emotions. Cambridge University Press, New York, reprinted 1994 edition, 1988

Piaget, J. (1972). The Principles of Genetic Epistemology. London: Routledge \& Keegan Paul Ltd.

Paiva, A., Chaves, R., Piedade, M., Bullock, A., Andersson, G., \& Höök, K. (2003). Sentoy: A tangible interface to control the emotions of a synthetic character. Paper presented at the AAMAS 2003.

Petz. http://petz.ubi.com/ accessed Oct 2005 


\section{AND THEY BOTH LIVED HAPPILY EVER AFTER?}

Prendinger, H., \& Ishizuka, M. (2001). Let's talk! Socially intelligent agents for language conversation training. IEEE Transactions on Systems, Man, and Cybernetics - Part A: Systems and Humans, 31(5), 465-471.

Propp, Vladimir. (1928.) Morphology of the Folktale. University of Texas Press, 1998.

Real Lives (2005) http://www.educationalsimulations.com/ accessed Oct 2005

Rieber, L. (1996). Seriously Considering Play: Designing Interactive Learning Environments Based on the Blending of Microworlds, Simulations and Games. Education and Training Resource and Development, 44, 42-58.

Robertson, J., \& Good, J. (2004). Children's Narrative Development Through Computer Game Authoring. Paper presented at the Interaction Design with Children, Maryland.

Robertson, J., \& Oberlander, J. (2002). Ghostwriter: Educational Drama and Presence in a Virtual Environment. Journal of Computer Mediated Communication, 8(1).

Sarbin, T. ( 1986) (ed) Narrative Psychology: The Storied Nature of Human Conduct. New York: Praeger

Schoppers, M (1987) Universal Plans for Reactive Robots in Unpredictable Environments. IJCAI 1987: 1039-1046

Tomlinson, B, Downie, M., Berlin, M., Gray, J., Lyons, D., Cochran, J., Blumberg,B.,(2002) "Leashing the AlphaWolves: mixing user direction with autonomous Emotion in a Pack of Semi-Autonomous Virtual Characters." Proceedings of the 2002 ACM SIGGRAPH Symposium on Computer Animation. San Antonio, TX.

Tomlinson,B; J. Gray, M. L. Yau. (2005) "Multiple Virtual Rafts: A Multi-User Paradigm for Interacting with Communities of Autonomous Characters." In: Late Breaking Results (Interactive Poster), ACM Conference On Human Factors In Computing Systems (CHI 2005), Portland, OR.

Uncle Roy All Around You (2005) http://www.uncleroyallaroundyou.co.uk/ accessed Oct 2005

Vincent, A., \& Shepherd, J. (1998). Experiences in Teaching Middle East Politics via Internet-based Role-Play Simulations. Journal of Interactive Media in Education,(11).

Young, K. (2001) "The Neurology of Narrative" SubStance - Issue 94/95 (Volume 30, Number 1\&2), 2001, pp. 72-84 University of Wisconsin Press

\section{AFFILIATIONS}

Ruth Aylett

School of Mathematical and Computer Sciences,

Heriot-Watt University 